\title{
A Message from the Editor
}

Exactly one year ago, in the Editor's Message in Volume 120, Issue 1, I wrote that Public Health Reports and the Association of Schools of Public Health had made a decision to end our relationship with a publishing house and publish PHR ourselves. We made this decision to gain the flexibility we needed to address a growing problem of manuscript backlog and to increase the Journal content. It was an intimidating move that we did not approach lightly. But it was clear that such a move was necessary if we wanted to make the Journal bigger to reduce waiting time, yet avoid taking on commercial advertising that would possibly be at odds with good public health practice

We have now been self-publishing for a full year. I am very happy to say that the Journal is bigger, better, and on time. We are in excellent shape as we start 2006. I am even happier to say that while we are all working at times unbelievably hard, it has been tremendous fun. Having fun with what you are doing seems to be the key ingredient in the formula for sustained hard work and new and better things. For instance, by the time you read this, you will be able to access the entire collection of Public Health Reports from 1878, on-line and free of charge. The entire 127 years will be full-text searchable. This is something public health historians will treasure, because the $P u b$ lic Health Reports collection has long been a primary source for those looking for a window into the past. But it will also be a treat for all public health practitioners, academics, and students who will be able to gain personal perspective by examining our experience as a developing society struggling to pursue a life free of preventable disease. And what a picture this is. From the weekly reports of diagnosed cases of yellow fever and diphtheria, to the eradication of smallpox and the conquering of polio, the intellectual time traveler can actually witness the effects of largely uncontrolled disease on a beleaguered population and how intervention by public health-minded individuals liberated humankind from nearly unfathomable suffering. I think many of you will find, as I did, that looking back also provides the energy to look forward. For we are still faced with challenges to our general health and welfare, and we have a long way to go before we rest.

Self-publishing has led to other Journal projects as well. To celebrate the availability of the full collection, we have produced our first book, Public Health Reports: Historical Collection 1878-2005. It is a look at many of the seminal articles that have appeared in Public Health
Reports over the last 127 years, written by extraordinary public health practitioners. Included with these historical articles are commentaries-written by currentday public health luminaries-that provide insights into the significance of the articles and the accomplishments of those who wrote them. This book will be printed in a limited edition, but later this year it will be made available to everyone as a printed supplement to the Journal, again free of charge. (If you are interested in obtaining a copy of the limited edition, drop me an e-mail and I'll supply you with ordering information.) Hopefully there will be other books to follow.

We also learned how to do color in 2005. For the first time in our history, the Journal included color photographs. Our September/October 2005 issue included a photo essay depicting the devastation wrought by the December 26, 2004, tsunami in Thailand. Our experience primarily showed us that using color in the Journal is expensive. But when it is essential, as in these dramatic photographs, we can and will do it.

We decided that the Journal can become a more important player in the classroom. PHR and ASPH are working on several plans to make that happen, including distance learning classes based on PHR content. This should be helpful to students and teachers as well. There are other new things under development at PHR. And if our increasing subscription sales and manuscript submissions are any indication, people are liking what they see in PHR. We hope so.

How do we know when the public's health is evolving in the right direction? In this issue, Stephen Thacker and his co-authors at the Centers for Disease Control and Prevention explain that CDC is committed to finding new and more meaningful ways to measure health. In "Measuring the Public's Health," they explain that the traditional health indices of disability, injury, and death are no longer sufficient. The authors call for collaboration in the effort to fundamentally change how health is measured.

The Pregnancy Risk Assessment Monitoring System (PRAMS) is an ongoing national reproductive health follow-back survey. Milton Kotelchuck provides his insight on how an expanded PRAMS could improve maternal and child health research and lead to their improved health status.

Much of what we know in public health, or think we know, comes from data collected by surveys. But as all epidemiology students learn very early in their studies, 
collection of valid data from surveys is fraught with pitfalls. Sometimes students believe the primary purpose of survey design is to cause them great discomfort when taking examinations on the subject. Even people who have been administering surveys for years are periodically surprised by the way creation, administration, and evaluation of an instrument can influence the outcome. Mixed-mode surveys are becoming increasingly common in attempts to address the problems of survey data. That's why I am delighted when a survey methodology paper is submitted. In his article, Don Dillman explains some of the challenges of a mixed-mode survey. This is a must-read paper for people in the business.
After the recent tsunami, hurricanes Katrina, Rita, Wilma, and the Pakistan earthquake, it is hard to even remember the 2003 blackout in the Northeast United States. But not if you were in it. Mark Beatty and colleagues at the New York City Department of Health and Mental Hygiene took a hard look at the lessons learned from the blackout of 2003. Beatty et al. examined shortcomings of the response and solutions recommended to increased future preparedness. These same solutions are easily generalizable to all such emergencies.

Robert A. Rinsky, PhD

\section{ERRATUM}

In Volume 120, No. 6, page 643, the Table was incorrect in the article "Child Labor, Gender, and Health." The correct table appears below:

Table. Comparison of literacy rates between males and females and the mortality rate for children younger than 5 years of age

\begin{tabular}{|c|c|c|c|c|c|}
\hline \multirow[t]{2}{*}{ Country } & \multicolumn{2}{|c|}{ Literacy rate 1990} & \multicolumn{2}{|c|}{ Literacy rate 2000} & \multirow{2}{*}{$\begin{array}{c}\text { Mortality rate } \\
\text { per 1,000 live births } \\
\text { (birth-age 5) } \\
2001\end{array}$} \\
\hline & Males & Females & Males & Females & \\
\hline Afghanistan & 40 & 12 & 51 & 21 & 257 \\
\hline Angola & 56 & 29 & - & - & 208 \\
\hline Liberia & 55 & 23 & 70 & 37 & 190 \\
\hline Nicaragua & 61 & 61 & 64 & 64 & 36 \\
\hline Niger & 18 & 5 & 23 & 8 & 265 \\
\hline Pakistan & 49 & 20 & 57 & 28 & 107 \\
\hline Philippines & 93 & 92 & 96 & 95 & 29 \\
\hline
\end{tabular}

SOURCE: UNICEF. State of the world's children [cited 2005 Sep 2]. Oxford: Oxford University Press; 2003. Also available from: URL: http://www.unicef.org/sowc03/contents/pdf/SOWC03-eng.pdf 